\title{
Article \\ Mathematical Proof on the Existential Necessity of the World
}

Young H. Lee

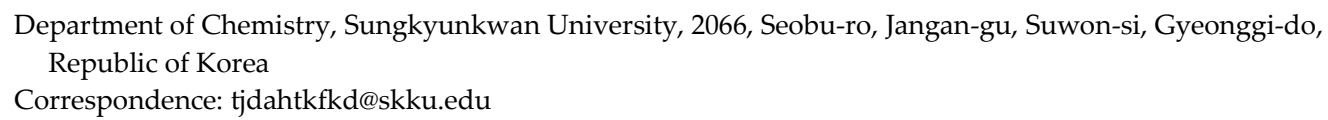

\begin{abstract}
The "best of all possible worlds" theory (hereinafter the "possible world theory") was presented by Leibniz many centuries ago, and provided an opportunity for metaphysics to understand the ontological meaning of the world in an in-depth way. Furthermore, the theory has multiple impacts on the multiverse theory of modern physics. However, considering the ontological questions of the world solely on linguistics logic leads to basing the possible world theory or the multiverse theory on relatively uncertain inferential reasons. In this study, symbolic logic was used to consider the possible world theory on a more solid foundation. The entire world was made into oneness, and tracking the existential process at the beginning of the world, realized the existential necessity of the world, even though the initial causal point of the world was assumed to be completely void (null set). The existential system in this study, was generalized without specific elements, apart from existence and non-existence. It was discovered that existential possibility and existential necessity are logically equivalent.
\end{abstract}

Keywords: Possible World, Theories of Universe, Origins of Universe, Existential Possibility, Existential Necessity

\section{Introduction}

One can consider the topic of examining the existential origins of the world to be the most important among the many topics considered in metaphysics [1]. However, philosophers have focused on other topics due to the profound and complex nature of this topic. At moments where the topics were about to be forgotten in the history of intellectual thought, masters of ontology would often remind others. Leibniz mentioned the concept of possible worlds in his book, Discourse of Metaphysics and other Essays, and said that the world of which we are part is "the best of all possible worlds" [2] (p.53-55). His possible world theory allowed various forms of modal logic ${ }^{1}$ to be researched in later generations, and has had a grave impact on the theories of universe in modern physics. ${ }^{2}$ Simultaneously, the lack of methodology could not allow the point of the argument's context to be seen in a clearer light. ${ }^{3}$ This paper examines the logical structure that makes it possible for existential necessity using methods from symbolic logic.

\section{Proof Process and Explanation}

First, we consider the entire world bundled up into oneness. The oneness of the world does not ignore the specific characteristics or structures within the world; rather, it simplifies the proof. Let us refer to the world bundled up into oneness as $\omega$.

$\varphi_{\mathrm{w}}$ is the existential position of such a world. Therefore, when $\omega$ is in existence, we define $\varphi_{w}$ to be included in $\varepsilon_{1}$, and when $\omega$ is not in existence, we define $\varphi_{w}$ as $\varepsilon_{0}$.

1. Refer to $[3,4,5]$ for further details on modal logic.

2. Specifically referring to the multiverse theory. Refer to [6,7] for further details.

3. W.V. Quine claims modern modal logic is also "metaphysically extravagant." Refer to [8]. 
First, the fact that the universe exists becomes clear, and therefore the proposition "it is possible for the world to exist" is naturally true. When we construct this into symbols, it is $\diamond \exists \omega$.

Contrarily, since it is possible for the world to exist, then the world will be at a crossroads between existence and non-existence. Thus, it must be either in the condition of existence or the condition of non-existence. If this is not the case, the world remains in an undefined state, even though the existence/non-existence state is possible, and therefore, this in itself becomes a contradiction. Thus, it is necessary for the world to choose an existential position.

$$
\diamond \exists \omega \rightarrow \square \exists \varphi_{\mathrm{w}}
$$

Here, the existential position $\varphi_{\mathrm{w}}$ cannot avoid the union of $\varepsilon_{1}$ and $\varepsilon_{0}$ since it is within that category in the first place. Expressing this, $\diamond \exists \varphi_{w} \rightarrow \square \forall \varphi_{w}\left[\varphi_{w} \in\left[\varepsilon_{1} \vee \varepsilon_{0}\right]\right]$. Moreover, $\square \exists \varphi_{w} \rightarrow \diamond \exists \varphi_{w}$ is always logically true, and we can rearrange the following as such:

$$
\begin{gathered}
\diamond \exists \omega \rightarrow \square \exists \varphi_{\mathrm{w}} \\
\square \exists \varphi_{\mathrm{w}} \rightarrow \diamond \exists \varphi_{\mathrm{w}} \\
\diamond \exists \varphi_{\mathrm{w}} \rightarrow \square \forall \varphi_{\mathrm{w}}\left[\varphi_{\mathrm{w}} \in\left[\varepsilon_{1} \vee \varepsilon_{0}\right]\right]
\end{gathered}
$$

$\beta(\varphi)$ is defined as a set of influencing elements that influence which position will be placed for the existential position $\varphi$. Let us suppose that $\Psi(\mathrm{x})$ depicts the degree of preferability that $x$ manifests as part of belonging to the system.

Then, $\beta(\varphi)$ and $\Psi(\varepsilon)$ are interrelated. For instance, if $\beta(\varphi)$ includes a God with good morality as the sole element, $\Psi\left(\varepsilon_{1}\right)>\Psi\left(\varepsilon_{0}\right)$. On the other hand, if the sole element is not a God, but a demon who likes to nihilate everything, it will be $\Psi\left(\varepsilon_{1}\right)<\Psi\left(\varepsilon_{0}\right)$. However, in this proof, the world was introduced as oneness that includes everything; therefore, we assume that no elements influenced existential positions into existence or non-existence. Even if there is a God or a demon, and it cannot be proved that they are self-generating beings, they are considered part of the world category.

Therefore, as indicated above, the world must begin with absolute nothingness in the flow of cause and effect for the ontological proof of the general world to be meaningful. Therefore, $\beta\left(\varphi_{\mathrm{w}}\right) \rightarrow \Phi$. If we consider $\beta(\varphi)$, which is a function of the general existential position, it is self-evident that $[\beta(\varphi) \rightarrow \Phi] \rightarrow\left[\Psi\left(\varepsilon_{1}\right)=\Psi\left(\varepsilon_{0}\right)\right]$. If there are no elements that influence the existential position, there cannot be a difference in the preferences for existence and non-existence, respectively. Therefore, $\varepsilon_{1}$ and $\varepsilon_{0}$ are preferred to equal degrees $\left(\Psi\left(\varepsilon_{1}\right)=\Psi\left(\varepsilon_{0}\right)\right)$. However, if $\Psi\left(\varepsilon_{1}\right)=\Psi\left(\varepsilon_{0}\right)$, then it is not possible for position $\varphi$ to selectively choose only one of either $\varepsilon_{1}$ or $\varepsilon_{0}$. It is necessary for the difference in preference between the two choices to follow in specific choices. Therefore, $\varphi$ belongs to the intersection of $\varepsilon_{1}$ and $\varepsilon_{0}$ or the intersection of the complementary set of each set. In other words, existence and non-existence must both manifest for $\omega$, or both will not manifest. For the simultaneous manifestation of existence and non-existence, one existential system must be divided into two systems. If we express the point above into the equations, it is as follows:

$$
\begin{gathered}
{[\beta(\varphi) \rightarrow \Phi] \rightarrow\left[\Psi\left(\varepsilon_{1}\right)=\Psi\left(\varepsilon_{0}\right)\right]} \\
{\left[\Psi\left(\varepsilon_{1}\right)=\Psi\left(\varepsilon_{0}\right)\right] \rightarrow \square \forall \varphi\left[\varphi \in\left[\varepsilon_{1} \wedge \varepsilon_{0}\right] \vee\left[\neg \varepsilon_{1} \wedge \neg \varepsilon_{0}\right]\right]} \\
\beta\left(\varphi_{\mathrm{w}}\right) \rightarrow \Phi \\
\therefore \square \forall \varphi_{\mathrm{w}}\left[\varphi_{\mathrm{w}} \in\left[\varepsilon_{1} \wedge \varepsilon_{0}\right] \vee\left[\neg \varepsilon_{1} \wedge \neg \varepsilon_{0}\right]\right]
\end{gathered}
$$

$\forall \forall \varphi_{w}\left[\varphi_{w} \in\left[\varepsilon_{1} \vee \varepsilon_{0}\right]\right]$ is true from the above equation (3), and when the two conclusions $(3,7)$ are combined, it can be expressed as follows:

$$
\square \forall \varphi_{\mathrm{w}}\left[\varphi_{\mathrm{w}} \in\left[\varepsilon_{1} \vee \varepsilon_{0}\right] \wedge\left[\left[\varepsilon_{1} \wedge \varepsilon_{0}\right] \vee\left[\neg \varepsilon_{1} \wedge \neg \varepsilon_{0}\right]\right]\right]
$$


It is expressed as $\square \forall \varphi_{w}\left[\varphi_{w} \in\left[\varepsilon_{1} \vee \varepsilon_{0}\right] \wedge\left[\left[\varepsilon_{1} \wedge \varepsilon_{0}\right] \vee\left[\neg \varepsilon_{1} \wedge \neg \varepsilon_{0}\right]\right]\right] \rightarrow \square \forall \varphi_{w}\left[\varphi_{w} \in\left[\varepsilon_{1} \wedge \varepsilon_{0}\right]\right]$, and it is expressed as $\square \forall \varphi_{w}\left[\varphi_{w} \in\left[\varepsilon_{1} \wedge \varepsilon_{0}\right]\right] \rightarrow \square \forall \varphi_{w}\left[\varphi_{w} \in \varepsilon_{1}\right]$. We then merge it with equation (1) $\left(\diamond \exists \omega \rightarrow \square \exists \varphi_{w}\right)$, and express it as $\square \exists \varphi_{w} \wedge \square \forall \varphi_{w}\left[\varphi_{w} \in \varepsilon_{1}\right]$. It leads to the conclusion $\square \exists \omega$. If the existential position of $\omega$ inevitably exists, and if all the positions that exist belong to the area of existence $\left(\varepsilon_{1}\right)$, then $\omega$ will inevitably exist. Therefore, it can be concluded that $\square \exists \varphi_{\mathrm{w}} \wedge \square \forall \varphi_{\mathrm{w}}\left[\varphi_{\mathrm{w}} \in \varepsilon_{1}\right] \rightarrow \square \exists \omega$, and if we rearrange the entire proof, it can be expressed as $\diamond \exists \omega \rightarrow \square \exists \omega$; the opposite of $\diamond \exists \omega \rightarrow \square \exists \omega$, which is $\square \exists \omega \rightarrow \diamond \exists \omega$, and is logically always true. Naturally, $\diamond \exists \omega$ and $\square \exists \omega$ become logically equivalent. Therefore, $\diamond \exists \omega \leftrightarrow \square \exists \omega$ is established. This means that in a generalized existential environment, without specific elements, except existence $\left(\varepsilon_{1}\right)$ and non-existence $\left(\varepsilon_{0}\right)$, the possibility of existence and necessity of existence is logically equivalent.

If we express the entire proof process, it can be expressed as follows:

$$
\begin{gathered}
\diamond \exists \omega \rightarrow \square \exists \varphi_{\mathrm{w}} \\
\square \exists \varphi_{\mathrm{w}} \rightarrow \diamond \exists \varphi_{\mathrm{w}} \\
\diamond \exists \varphi_{\mathrm{w}} \rightarrow \square \forall \varphi_{\mathrm{w}}\left[\varphi_{\mathrm{w}} \in\left[\varepsilon_{1} \vee \varepsilon_{0}\right]\right] \\
{[\beta(\varphi) \rightarrow \Phi] \rightarrow\left[\Psi\left(\varepsilon_{1}\right)=\Psi\left(\varepsilon_{0}\right)\right]} \\
{\left[\Psi\left(\varepsilon_{1}\right)=\Psi\left(\varepsilon_{0}\right)\right] \rightarrow \square \forall \varphi\left[\varphi \in\left[\varepsilon_{1} \wedge \varepsilon_{0}\right] \vee\left[\neg \varepsilon_{1} \wedge \neg \varepsilon_{0}\right]\right]} \\
\beta\left(\varphi_{\mathrm{w}}\right) \rightarrow \Phi \\
\therefore \forall \forall \varphi_{\mathrm{w}}\left[\varphi_{\mathrm{w}} \in\left[\varepsilon_{1} \wedge \varepsilon_{0}\right] \vee\left[\neg \varepsilon 1 \wedge \neg \varepsilon_{0}\right]\right] \\
\left.\therefore \square \varphi_{\mathrm{w}}\left[\varphi_{\mathrm{w}} \in\left[\varepsilon_{1} \vee \varepsilon_{0}\right] \wedge\left[\left[\varepsilon_{1} \wedge \varepsilon_{0}\right] \vee\left[\neg \varepsilon_{1} \wedge \neg \varepsilon_{\mathrm{w}}\right]\right]\right] \rightarrow \square \forall \varphi_{\mathrm{w}} \in\left[\varepsilon_{1} \vee \varepsilon_{0}\right] \wedge\left[\left[\varepsilon_{1} \wedge \varepsilon_{0}\right] \vee\left[\neg \varepsilon_{\mathrm{w}} \wedge \neg \varepsilon_{0}\right]\right]\right] \\
\square \forall \varphi_{\mathrm{w}}\left[\varphi_{\mathrm{w}} \in\left[\varepsilon_{1} \in\left[\varepsilon_{1} \wedge \varepsilon_{0}\right]\right] \rightarrow \square \forall \varphi_{\mathrm{w}}\left[\varphi_{\mathrm{w}} \in \varepsilon_{1}\right]\right. \\
\square \exists \varphi_{\mathrm{w}} \wedge \square \forall \varphi_{\mathrm{w}}\left[\varphi_{\mathrm{w}} \in \varepsilon_{1}\right] \rightarrow \square \exists \omega \\
\therefore \diamond \exists \omega \rightarrow \square \exists \omega
\end{gathered}
$$

\section{Conclusion}

As mentioned previously, it is not possible for the simultaneous manifestation of existence $\left(\varepsilon_{1}\right)$ and non-existence $\left(\varepsilon_{0}\right)$ in a single system. In addition, there is no causal effect when choosing only one of either $\varepsilon_{1}$ or $\varepsilon_{0}$. However, it is also contradictory to remain in an undefined state. Therefore, it is necessary for a single system to be separated into two to overcome this state. Thus, one system retains the essence, but the quantity increases to two. Furthermore, it was defined that the whole world will be considered as one category at the beginning of the proof. Therefore, both existential systems are elements that influence the ontological status of $\omega . \varepsilon 1$ and $\varepsilon_{0}$ are separately manifested in the two systems, and the fact that it is possible to position the two systems into one category shows that it is possible to introduce the union of $\varepsilon_{1}$ and $\varepsilon_{0}$. At this moment, it may appear that the manifestation of $\varepsilon_{1}$ and $\varepsilon_{0}$ in the respective systems is a contradiction. When there is an existential system, is it not possible that only one between $\varepsilon_{1}$ and $\varepsilon_{0}$ is selected and manifested? However, such a phenomenon cannot be applied to systems that are divided into two types. The contradiction already occurred in the single-system state prior to its division into two. To resist this contradiction, the two systems were created, and in it, $\varepsilon_{1}$ and $\varepsilon_{0}$ were manifested. Therefore, there is a force for $\varepsilon_{1}$ and $\varepsilon_{0}$ to manifest in each system. The force, namely, is the power that resists the contradiction.

Funding: This research received no external funding. 
Acknowledgments: I am extremely grateful to the authors of books and articles those were included as references of this paper. I also thank MDPI for helping to publish this paper.

Conflicts of Interest: The author declares no conflict of interest.

\section{References}

1. Heidegger, M. Introduction to Metaphysics, $2^{\text {nd }}$ Ed.; Translated by Fried, G.; Polt, R. Yale University Press: New Haven, CT, 1997, pp. 24-25.

2. Leibniz, G. Discourse on Metaphysics and Other Essays. Translated by Garber, D.; Ariew, R. Hackett Publishing: Indianapolis, IN, 1991, pp. 53-55.

3. Thomas, A.D. Extended modal realism - a new solution to the problem of intentional inexistence. Philosophia 2020, 48(3), 1197-1208.

4. Lewis, D. On the Plurality of Worlds. Wiley-Blackwell: Hoboken, NJ, pp. 127-128.

5. Vacek, M. Extended modal dimensionalism. Acta Analytica 2017, 32(1), 13-28. doi:10.1007/s12136-016-0297-9.

6. Tegmark, M. Parallel Universes. In Science and Ultimate Reality: From Quantum to Cosmos, Honoring John Wheeler's 90th Birthday. Barrow, J.D; Davies, P.C.W.; Harper, C.L., Eds 2003, 288 (5): pp. 40-51.

7. Deutsch, D. The ends of the Universe. In The Fabric of Reality: The Science of Parallel Universes —and Its Implications. Penguin Press: London, 1997.

8. Quine, W.V. Proportional Objects. In Ontological Relativity and Other Essays. Columbia University Press: New York, NY, 1969, pp. 140-147. 